\title{
FILM PENDEK ANIMASI TIGA DIMENSI PADA TAHFIDZ ANAK USIA DINI (TAUD) AL-FATIH PEKANBARU
}

\author{
Nurhayati, Melly Novalia, Pratama Benny Herlandy \\ Program Studi Pendidikan Informatika FKIP Universitas Muhammadiyah Riau \\ Jl. Tuanku Tambusai, Pekanbaru, 28294 Riau \\ e-mail: mellynovalia@umri.ac.id
}

\begin{abstract}
ABSTRAK
Proses pembelajaran pada TAUD Al-Fatih Pekanbaru menampilkan murottal AlQur'an juz ke-30 tanpa adanya penjelasan dari makna setiap Surah tersebut. Tujuan penelitian adalah mengembangkan media pembelajaran film pendek animasi tiga dimensi serta mengukur kelayakan media pembelajaran film pendek animasi tiga dimensi. Jenis Penelitian adalah $(R \& D)$ dari model Four-D. Hasil penelitian pengembangan media pembelajaran menunjukkan 1) review ahli materi tahap I memperoleh skor 87,75; 2) review ahli materi tahap II memperoleh skor 96,65; 3) review ahli media tahap I memperoleh skor 80,24; 4) review ahli media tahap II memperoleh skor 88,12; 5) review ahli media tahap III memperoleh skor 91,58. Hasil uji terbatas, 1) pengamatan peserta didik memperoleh skor 0,60; 2) respon tenaga pendidik memperoleh skor 0,56. Hasil uji media, 1) pengamatan peserta didik memperoleh skor 0,84 ; 2) respon tenaga pendidik memperoleh skor 0,9. Disimpulkan media pembelajaran berbasis film pendek animasi tiga dimensi pada TAUD Al-Fatih Pekanbaru dinyatakan layak dan selesai dikembangkan.
\end{abstract}

\section{Kata kunci : Film Pendek, Animasi 3D, Usia Dini}

\begin{abstract}
The learning process in the TAUD Al-Fatih Pekanbaru requires the students to do Qur'an murottal at the 30th juz without any explanation of the meaning of each of the Surah. The purpose of this research is to develop three-dimensional animated short film learning media and measure the feasibility of three-dimensional animated short film learning media. This type of research is $(R \& D)$ from the Four-D model. The results of research in the development of instructional media show that 1) material expert review of stage I obtained a score of 87.75; 2) material expert review of stage II obtained a score of 96.65 ; 3) media expert review of stage 1 obtained a score of 80.24; 4) media expert review of the stage II obtained a score of 88.12; 5) media expert review of stage III obtained a score of 91.58. Limited test results reveal that 1) observations of students get a score of $0.60 ; 2)$ the response of educators obtained a score of 0.56. The results of the media test show that 1) the observation of students obtained a score of $0.84 ; 2)$ the response of educators obtained a score of 0.9 . It can be concluded that the learning media based on a three-dimensional animated short film at TAUD Al-Fatih in Pekanbaru can be stated feasible and completed.
\end{abstract}

Keywords: Short Film, Three-dimensional Animation, Surah Al-Lail, Early Age 


\section{Pendahuluan}

Dalam dunia pendidikan tahfidz memiliki jenis media pembelajaran yang beragam dan metode pembelajaran yang digunakan agar peserta didik mudah dalam menghafal Al-Qur'an, namun perlu diperhatikan bahwa tidak semua metode tersebut dapat dengan mudah diterapkan pada peserta didik. Berdasarkan hasil observasi pada TAUD Al-Fatih Pekanbaru menggunakan metode tabarak, sebuah metode yang mulai menghapal sejak usia 3 tahun. Pada masa-masa awal menghafal, metode ini belum menghafal Al-Qur'an dengan cara membaca. Bacaan Al-Quran hanya diperdengarkan sambil mulai diperkenalkan pada huruf dan harakat Al-Qur'an, yang dimana metode ini menggunakan proyektor sebagai media bantu. Namun media bantu untuk menunjang metode tabarak ini kurang kreatif sehingga peserta didik mudah menjadi bosan dan masih sulit untuk fokus dalam jangka waktu yang lama. Hal ini disebabkan oleh tampilan media berbentuk video rekaman orang yang sedang membacakan Al-Qur'an (Murottal Al-Qur'an) juz ke-30 untuk ditontonkan dan diperdengarkan kepada peserta didik. Menontonkan murottal AlQur'an juz ke-30 dalam waktu yang lama akan membuat peserta didik mengalami kesulitan fokus atau peserta didik mudah menjadi bosan dan media seperti itu terlalu monoton untuk peserta didik.

Pembelajaran pada TAUD Al-Fatih memang mengutamakan hafalan Al-Qur'an juz ke-30 akan tetapi tenaga pendidik tidak menjelasan tentang makna dari setiap Surah Al-Qur'an yang peserta didik hafalkan. Sehingga peserta didik hanya bisa melantunkan surah-surah Al-Qur'an yang sudah dihafalkan tanpa mengetahui makna atau isi kandungan Surah Al-Qur'an. Fase peserta didik pada usia tersebut masih berimajinasi, oleh sebab dibutuhkan strategi dan media yang sesuai dengan perkembangan peserta didik. Peserta didik pada fase imajinasi sangat menyukai gambar-gambar bergerak atau animasi. Seharusnya tenaga pendidik menyediakan media pembelajaran untuk menguatkan ingatan hafalan dan pemahaman terhadap makna Surah Al-Qur'an yang sudah di hafalkan oleh peserta didik, sehingga akan membantu perkembangan berpikir pra operasional anak usia dini.

Menurut John Piaget dalam [1] tahapan pra operasional mengemukakan bahwa tahapan ini membentang usia dua hingga tujuh tahun, perubahan paling jelas yang terjadi adalah peningkatan luar biasa dalam aktivitas representasi atau simbolis. Pada tahapan ini konsep yang stabil dibentuk, penalaran muncul, egosentris mulai kuat dan kemudia mulai melemah, serta bentuknya keyakinan terhadap hal yang magis. Dalam pra operasional menunjukkan bahwa pada tahapan ini teori Piaget difokuskan pada keterbatasan pemikiran anak. Istilah "operasional" menunjukkan pada aktifitas mental yang memungkinkan anak untuk memikirkan peristiwa pengalaman yang dialaminya.

\section{Metode Penelitian}

Jenis penelitian yang digunakan dalam penelitian ini adalah penelitian dan pengembangan dengan pendekatan deskriptif yang berorientasi pada pengembangan produk. Menurut Sukmadinata dalam [2] menjelaskan Research and Development (R\&D) adalah sebuah startegi penelitian yang cukup ampuh untuk memperbaiki praktek. Lebih lanjut dijelaskan bahwa penelitian dan pengembangan adalah suatu proses atau langkah-langkah untuk mengembangkan suatu produk baru atau menyempurnakan produk yang telah ada, yang dapat dipertanggung jawabkan. Dalam desain penelitian pengembangan ini penelitian memilih model Four-D, model ini dikembangkan oleh Sivasailam Thiagarajan, Dorothy S. Semmel, dan Melvyn I. Semmel. Trianto dalam [3] model ini di pandang sebagai model untuk pengembangan instruksional dengan tahapan define, design, develop, dan disseminate. 


\subsection{Tahap Define}

Tahap define bertujuan menganalisis kebutuhan (need assessment) sasaran, tahapan didalam proses analisispun mengadapsi taksonomi variabel pembelajaran dari Reigeluth dalam [4]. analisis kebutuhan media dilakukan dengan cara observasi bahwa media pembelajaran hanya berbentuk video muraratal Al-Qur'an yang hanya mendengarkan lantunan ayat demi ayat serta menampilkan ayat-ayat di dalam salah satu Surah Al-Qur'an. Media pembelajaran tidak menampilkan cerita dari setiap Surah yang peserta didik hafalkan serta tidak tidak adanya menggunakan animasi-animasi yang bergerak. Dan alat bantu yang digunakan untuk menyalurkan media pembelajaran tersebut yakni proyektor. Analisis peserta didik dilakukan dengan cara wawancara kepada peserta didik dan menyatakan kebanyakan mereka memang menyukai film animasi, hal ini seperti halnya dengan yang diungkapkan Parmiter dan Elkerton dalam [4] yakni anggota dalam kelompok animasi lebih menikmati pembelajaran daripada dalam kelompok teks atau tulisan.

Analisis materi, peneliti menarik kesimpulan bahwasanya selama penyajian materi tenaga pendidik hanya memberikan hafalan-hafalan ayat saja, kemudian tidak adanya menjelaskan atau menontonkan makna dari apa yang peserta didik hafalkan. Analisis bahasa, yakni tenaga pendidik menggunakan bahasa yang mudah di mengerti oleh peserta didik. Untuk menindaklanjuti kebutuhan tersebut, tahap design dilakukan dan diawali dengan penyusunan materi dalam film pendek animasi tiga dimensi disesuaikan dengan kebutuhan pembelajaran di TAUD Al-Fatih Pekanbaru, materi yang sudah ditentukan disesuaikan dan didokumentasikan kedalam naskah pengembangan media pembelajaran film pendek animasi tiga dimensi. Langkah selanjutnya penyusunan instrument, instrument disusun dan disesuaikan dengan produk yang dikembangkan, penyesuaian terhadap produk agar evaluasi yang dilakukan dapat tepat sasaran. Instrument yang disusun berupa instrument ahli materi, instrument ahli media, instrument respon tenaga pendidik, dan instrument pengamatan peserta didik.

\subsection{Tahap Design}

Tahap design selesai dilakukan, media film pendek animasi tiga dimensi lantas masuk ketahap pengembangan, tahap ini bertujuan untuk menghasilkan produk film pendek animasi tiga dimensi difokuskan pada lama durasi yang disesuaikan dengan rentang konsentrasi peserta didik [5]. Neville dalam (Romadhona 2017) by 5, most children can ignore minor distractions. Alone, they will focus on a single interesting activity for 10 or 15 minutes and on an assigned task for 4-6 minutes if it's easy and interesting. Setelah film pendek animasi tiga dimensi masuk ke dalam pengujian konseptual oleh ahli materi dan ahli media (review).

\subsubsection{Penyusunan Konten dan Naskah}

Penyusunan konten film pendek animasi tiga dimensi mengacu pada makna Surah Al-Lail di TAUD Al-Fatih Pekanbaru. Selain itu dilakukan juga diskusi dengan ahli materi yakni Bapak Dr. Muhammad Syahrullah, S.E., M.M dimana hasil diskusi ini berharap isi konten dari film pendek animasi tiga dimensi yang dikembangkan dekat dengan keseharian peserta didik. 


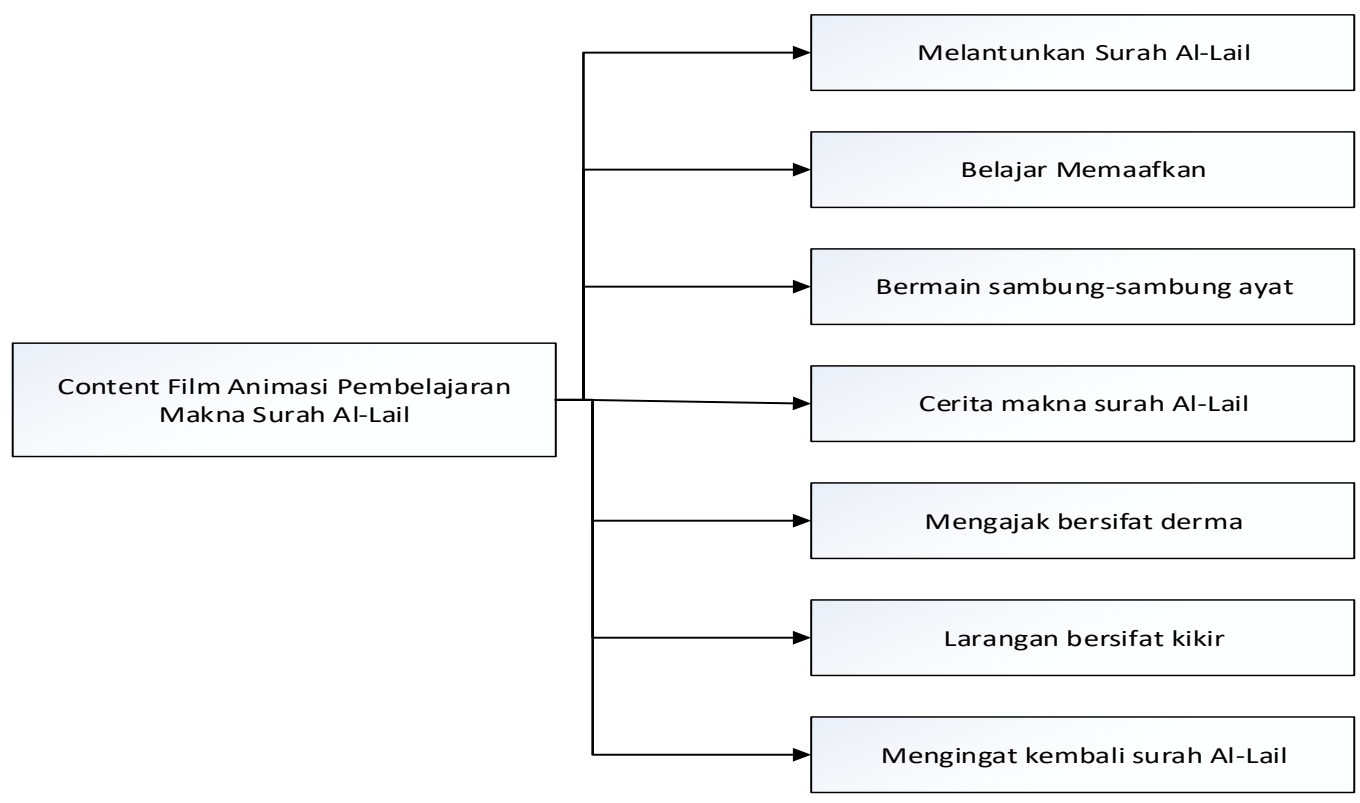

Gambar 1 Konten Film Pendek Animasi Tiga Dimensi

Setelah konten film pendek animasi tiga dimensi tersusun langkah selanjutnya adalah mengembangkan konten ke dalam sebuah satu kesatuan alur film pendek animasi tiga dimensi

Tabel 1 Alur Cerita Film Pendek Animasi Tiga Dimensi

\begin{tabular}{|l|l|l|}
\hline \multicolumn{1}{|c|}{ Segmen } & \multicolumn{1}{c|}{ Bentuk Segmen } & \multicolumn{1}{c|}{ Pelaku } \\
\hline Pembukaan & Lantunan Surah Al-Lail & Yusuf \\
\hline Segmen I & Belajar memaafkan & Yusuf, Ali dan Ibu \\
\hline Segmen II & Bermain sambung-sambung ayat & Yusuf, Ali dan Ayah \\
\hline Segmen III & Cerita makna Surah Al-Lail & Yusuf, Ali dan Ayah \\
\hline Segmen IV & Mengajak bersifat berderma & Yusuf, Ali dan Ibu \\
\hline Segmen V & Larangan bersifat kikir & Yusuf dan Ali \\
\hline Segmen VI & $\begin{array}{l}\text { Mengingatkan kembali makna } \\
\text { Surah Al-Lail }\end{array}$ & Yusuf dan Ali \\
\hline Penutup & Menampilkan pengisi suara & - \\
\hline
\end{tabular}

Setelah penyusunan materi makna Surah Al-Lail kedalam alur cerita film pendek animasi tiga dimensi, langkah selanjutnya adalah membuat tiap adegan (treatment). Treatment sendiri dapat diartikan sebagai kegiatan menyusun setiap adegan agar cerita menjadi lebih menarik dan sesuai dengan alur film pendek animasi tiga dimensi. Setelah treatment selesai disusun langkah selanjutnya adalah menyusun naskah, menyusun naskah sendiri adalah kegiatan membagi setiap shot/pengambilan gambar sehingga dapat menjadi satu kesatuan film pendek animasi tiga dimensi untuk dilihat. 

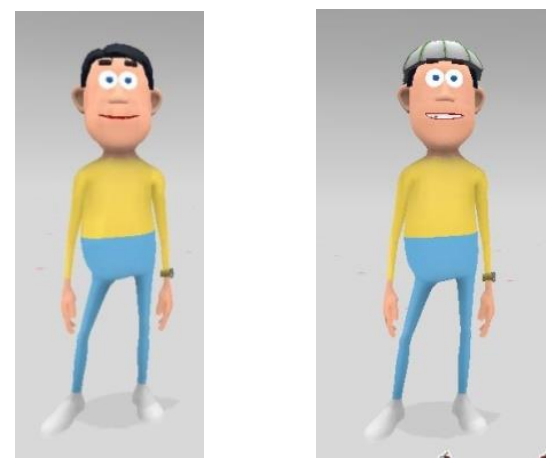

Gambar 2 Tokoh Yusuf

Yusuf merupakan tokoh utama di dalam film pendek animasi tiga dimensi. Yusuf adalah pribadi yang riang, bersemangat, percaya diri, penyayang, suka berderma, jahil terhadap adiknya serta suka menasehati adiknya jikalau berbuat kesalahan. Karakter Yusuf menggambarkan karakter anak-anak yang termasuk ke dalam tahap pra operasional kongkrit. Tokoh utama Yusuf dikemas dengan dua versi yang pertama untuk melantunkan Surah Al-Lail, dan yang kedua ketika berada didalam rumah.

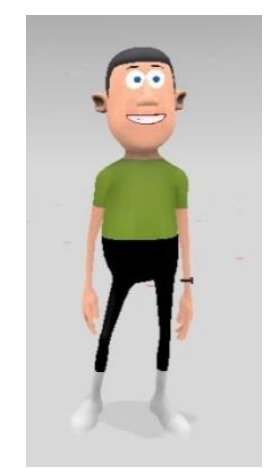

\section{Gambar 3 Tokoh Ali}

Ali merupakan adik dari Yusuf di dalam film pendek animasi tiga dimensi. Ali adalah pribadi yang periang, bersemangat, percaya diri, cengeng dan rasa ingin tahunya yang besar. Karakter Ali menggambarkan karakteristik anak usia dini yang termasuk kedalam tahap pra operasional kongkrit. Tokoh Ali dikemas menggunakan menggunakan pakaian atasan warna hijau dan pakaian bawahan warna hitam, dimana pemilihan warna tersebut bertujuan untuk menarik perhatian peserta didik.

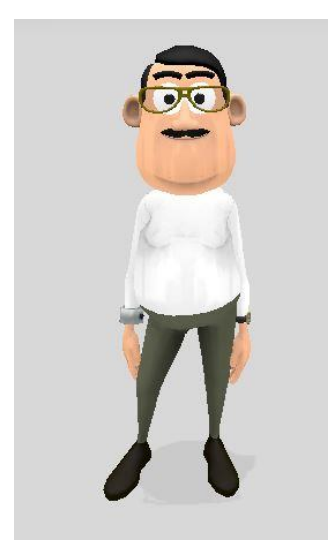

Gambar 4 Tokoh Ayah 
Tokoh ayah merupakan pemimpin keluarga, sosok ayah juga selalu menanamkan ajaran dari Al-Qur'an. Ayah juga selalu mengajak anak-anaknya bermain sambung-sambung ayat guna meningkatkan ingatan hafalan Al-Qur'an serta diselingin dengan menceritakan makna-makna dari setiap ayat maupun Surah Al-Qur'an yang anak-anaknya hafalkan. Selain itu ayah juga sosok yang penyabar, ketika anak-anaknya bertanya dan dijelaskan secara perlahan hingga paham.

Tokoh ibu merupakan tokoh pendukung karakter utama. Ibu sendiri merupakan pribadi yang yang penyayang, penyabar, penasehat, dan penuh perhatian. Karakter ibu sengaja tidak ditampilkan secara keseluruhan kedalam film pendek animasi tiga dimensi disebabkan aplikasi Muvizu yang digunakan tidak adanya menyediakan atribut untuk pakaian yang muslimah bagi perempuan. Sehingga sosok ibu hanya di tampilkan setengah dari badan dan pengambilan shot sosok ibu diambil dari arah belakang.

\subsection{Tahap Develop}

Dalam uji terbatas film pendek animasi tiga dimensi mendapatkan kategori layak penilaian respon pengamatan peserta didik, ddan peerta didik antusias serta menikmati setiap menit hingga selesai. Tak hanya itu, hasil respon tenaga pendidik menyatakan layak dan tenaga pendidik tertarik untuk menggunakan film pendek animasi tiga dimensi dalam pembelajaran dikelas. Produk kemudian masuk ke dalam tahap uji terakhir yakni uji media, dimana produk digunakan dalam pembelajaran di dalam kelas, dan tenaga pendidik memegang kendali penuh. Hasil uji media dari media pembelajaran animasi tiga dimensi mendapatkan kategori layak dari respon pengamatan peserta didik dan tenaga pendidik.

Kemudian tahap evaluasi media yang dilakukan dalam menentukan kelayakan sebuah media pembelajaran. Perubahan hasil antara uji terbatas dan uji media respon pengamatan peserta didik disimpulkan masih dalam kategori layak mengingat kualitas peserta didik yang banyak sehingga membuat keunikan pada diri peserta didik semakin banyak dan beragam pula respon dan didapat. Hasil respon tenaga pendidik juga mengalami peningkatan, hasil tersebut menujukkan kesiapan tenaga pendidik dalam menggunakan media pembelajaran film pendek animasi tiga dimensi dalam pembelajaran di kelas. Setelah melalui prosedur pengembangan maka dapat disimpulkan bahwa media pembelajaran film pendek animasi tiga dimensi untuk peserta didik TAUD Al-Fatih Pekanbaru dinyatakan layak dan telah selesai dikembangkan. Tahap terakhir yakni tahap diseminasi, tahap penyebarluaskan media kepada tenaga pendidik. Tahap ini telah dilakukan pada tahap uji media.

Tabel 2 Hasil Review dari Ahli Materi

\begin{tabular}{|l|c|c|l|}
\hline Aspek Penilaian & $\sum$ Instrumen & Ahli Materi & Kategori \\
\hline Materi & 12 & 93 & Sangat Layak \\
\hline Bahasa \& Tipografi & 8 & 82,5 & Sangat Layak \\
\hline \multicolumn{2}{|c|}{ Rata-rata } & $\mathbf{8 7 , 7 5}$ & Sangat Layak \\
\hline
\end{tabular}

Secara keseluruhan hasil review ahli materi diatas mendapatkan skor 87,75, berdasarkan kriteria kelayakan produk [6] skor tersebut termasuk ke dalam kategori sangat layak. Namun ahli materi lantas memberikan penilaian sangat layak dengan revisi sesuai saran/catatan.

Tabel 3 Hasil Review Ahli Materi yang Kedua

\begin{tabular}{|l|c|c|l|}
\hline Aspek Penilaian & $\sum$ Instrumen & Ahli Materi & Kategori \\
\hline Materi & 12 & 98,3 & Sangat Layak \\
\hline Bahasa \& Tipografi & 8 & 95 & Sangat Layak \\
\hline \multicolumn{2}{|c|}{ Rata-rata } & $\mathbf{9 6 , 6 5}$ & Sangat Layak \\
\hline
\end{tabular}


Secara keseluruhan hasil review ahli materi di atas mendapatkan skor 96,65 berdasarkan kriteria kelayakan produk [6] skor tersebut termasuk ke dalam kategori sangat layak. Ahli materi lantas memberikan penilian sangat layak tanpa revisi dan boleh di uji cobakan, hasil tersebut membuat media film pendek animasi tiga dimensi sangat layak masuk ke tahap uji terbatas.

Tabel 4 Hasil Review Ahli Media

\begin{tabular}{|l|c|c|l|}
\hline Aspek Penilaian & $\sum$ Instrumen & Ahli Materi & Kategori \\
\hline Visual Media & 13 & 81,6 & Sangat Layak \\
\hline Audio Media & 7 & 82,9 & Sangat Layak \\
\hline Tipografi & 4 & 80 & Layak \\
\hline Bahasa & 3 & 86,7 & Sangat Layak \\
\hline $\begin{array}{l}\text { Pemrograman } \\
\text { Media }\end{array}$ & 2 & 70 & Layak \\
\hline \multicolumn{2}{|c|}{ Rata-rata } & $\mathbf{8 0 , 2 4}$ & Layak \\
\hline
\end{tabular}

Secara keseluruhan hasil review ahli media di atas mendapat skor 80,24, berdasarkan kriteria kelayakan produk [6] termasuk ke dalam kategori layak. Ahli media memberikan penilaian layak dengan revisi sesuai saran/catatan.

Tabel 5 Hasil Review Ahli Media yang Kedua

\begin{tabular}{|l|c|c|l|}
\hline Aspek Penilaian & $\sum$ Instrumen & Ahli Materi & Kategori \\
\hline Visual Media & 13 & 83,08 & Sangat Layak \\
\hline Audio Media & 7 & 94,2 & Sangat Layak \\
\hline Tipografi & 4 & 80 & Layak \\
\hline Bahasa & 3 & 93,3 & Sangat Layak \\
\hline $\begin{array}{l}\text { Pemrograman } \\
\text { Media }\end{array}$ & 2 & 90 & Sangat Layak \\
\hline \multicolumn{2}{|l|}{ Rata-rata } & $\mathbf{8 8 , 1 2}$ & Sangat Layak \\
\hline
\end{tabular}

Kemudian untuk keseluruhan hasil review ahli media kedua diatas mendapatkan skor 88,116 , berdasarkan kriteri kelayakan produk [6] termasuk kedalam kategori sangat layak. Namun ahli media memberikan nilai sangat layak dengan revisi kembali sesuai dengan saran/catatan. Catatan dari ahli media yakni ketika tokoh Ali menangis, air mata harus keluar dan gerakan tangan mengucek-mengucek mata tidak boleh putus-putus serta munculkan tokoh ibu di dapur dengan hanya menampilkan badan ibu tanmpak dari samping/belakang. Hilangkan suara langkah kaki dan digantukan dengan suara cuci piring.

Tabel 6 Hasil Review Ahli Media yang Ketiga

\begin{tabular}{|l|c|c|l|}
\hline Aspek Penilaian & Instrumen & Ahli Materi & Kategori \\
\hline Visual Media & 13 & 90,76 & Sangat Layak \\
\hline Audio Media & 7 & 97,14 & Sangat Layak \\
\hline Tipografi & 4 & 80 & Layak \\
\hline Bahasa & 3 & 100 & Sangat Layak \\
\hline Pemrograman Media & 2 & 90 & Sangat Layak \\
\hline \multicolumn{2}{|c|}{ Rata-rata } & $\mathbf{9 1 , 5 8}$ & Sangat Layak \\
\hline
\end{tabular}

Secara keseluruhan hasil review ahli media yang ketiga di ata mendapatkan skor 91,58, berdasarkan kriteria kelayakan produk [6] [7] skor tersebut termasuk kedalam kategori sangat layak. Ahli media lantas memberikan penilaian sangat layak tanpa revisi kembali dan boleh 
diuji cobakan, hasil tersebut membuat media pembelajaran berbasis film pendek animasi tiga dimensi sangat layak masuk ke tahap uji terbatas

\subsection{Tahap Disseminate}

Pada tahap diseminasi memiliki tujuan yakni menyebarluaskan produk media pembelajaran film pendek animasi tiga dimensi. Penyebaran produk media pembelajaran film pendek animasi tiga dimensi hanya dilakukan kepada TAUD Al-Fatih Pekanbaru dan penyebaran telah dilaksanakan ketika pengujian media yakni tenaga pendidik langsung menggunakan media pembelajaran kepada peserta didik.

\section{Hasil dan Pembahasan}

\subsection{Hasil Respon Tenaga Pendidik}

Tabel 7 Hasil Uji Terbatas Respon Tenaga Pendidik

\begin{tabular}{|l|c|l|l|}
\hline Aspek penilaian & Einstrumen & Hasil & Kategori \\
\hline Materi & 7 & 0,71 & Layak \\
\hline Media & 5 & 0,4 & Tidak layak \\
\hline \multicolumn{2}{|c|}{ Total } & $\mathbf{0 , 5 6}$ & Layak \\
\hline
\end{tabular}

Berdasarkan hasil uji terbatas respon tenaga pendidik, secara keseluruhan media pembelajaran mendapatkan nilai 0,56, yang jika dilihat dalam (Romadhona, 2017) termasuk ke dalam kategori layak. Tenaga pendidik merespon tentang keberadaan media pembelajaran animasi tiga dimensi membantu tenaga pendidik dan lebih mudah dalam mengondisikan peserta didik sehingga tenaga pendidik lebih mudah dalam menyampaikan materi yang diajarkan.

Tabel 8 Hasil Uji Media Respon Tenang Pendidik

\begin{tabular}{|c|c|c|c|}
\hline Aspek penilaian & Einstrumen & Hasil & Kategori \\
\hline Materi & 7 & 1 & Layak \\
\hline Media & 5 & 0,8 & Layak \\
\hline \multicolumn{2}{|c|}{ Total } & $\mathbf{0 , 9}$ & Layak \\
\hline
\end{tabular}

Secara keseluruhan hasil uji media respon tenaga pendidik mendapatlan skor 0,9 yang jika dilihat dalam (Romadhona, 2017) termasuk ke dalam kategori layak. Respon tenaga pendidik berupa keinginan jika kedepannya TAUD Al-Fatih Pekanbaru diajak bekerja sama dalam pengembangan media pembelajaran seperti halnya film pendek animasi tiga dimensi tentang Surah Al-Lail sehingga dari kerja sama tersebut akan menghasilkan media pembelajaran yang bisa digunakan dalam pembelajaran dikelas nantinya.

Tenaga pendidik juga mengungkapkan bahwa TAUD Al-Fatih Pekanbaru baru baru kali ini diajak bekerja sama dalam hal pengembangan media pembelajaran. Sebelumnya hanya mendapat hibah media pembelajaran yang tidak semua dari media itu bisa digunakan dalam proses pembelajaran dikelas.

\subsection{Hasil Pengamatan Peserta Didik}

Tabel 9 Hasil Uji Terbatas Pengamatan Peserta Didik

\begin{tabular}{|l|c|c|c|c|c|c|}
\hline \multicolumn{1}{|c|}{ Nama Siswa } & PM & PB & PK & PSE & Rata-rata & Kategori \\
\hline Alifa Rahmanda & 1 & 0,67 & 0 & 0,75 & 0,605 & Layak \\
\hline Al-Hafiz & 0,5 & 0,34 & 0 & 0,75 & 0,4 & Tidak layak \\
\hline Al-Path Faregus & 0 & 1 & 0 & 0,75 & 0,4375 & Tidak layak \\
\hline Aditia ainurahman & 0,5 & 0,67 & 1 & 0,75 & 0,48 & Tidak layak \\
\hline Anggi Arisha Dewi & 0,5 & 1 & 1 & 1 & 0,875 & Layak \\
\hline
\end{tabular}




\begin{tabular}{|l|c|c|c|c|c|c|}
\hline Febyola Dwi & 0,5 & 0,67 & 1 & 0,75 & 0,73 & Layak \\
\hline Galih Hendrawan & 0,5 & 0,67 & 0 & 0,75 & 0,48 & Tidak layak \\
\hline Humaidha & 1 & 0,67 & 1 & 1 & 0,9175 & Layak \\
\hline Intan Keisha & 0,5 & 1 & 0 & 0,75 & 0,5625 & Layak \\
\hline Khodijah Nur & 0,5 & 1 & 0 & 0,5 & 0,5 & Layak \\
\hline \multicolumn{6}{|c|}{ TOTAL } \\
\hline
\end{tabular}

\section{Catatan:}

$\mathrm{PM}=$ Aspek Perkembangan Moral

$\mathrm{PB} \quad=$ Aspek Perkembangan Bahasa

PK = Aspek Perkembangan Kognitif

PSE $\quad=$ Aspek Perkembangan Sosial Dan Emosi

Berdasarkan hasil uji terbatas pengamatan peserta didik, secara keseluruhan media pembelajaran berbasis film pendek animasi tiga dimensi mendapat skor 0,60, yang jika di lihat dalam (Romadhona, 2017) termasuk ke dalam kategori layak. Tanggapan peserta didik menonton film pendek animasi tiga dimensi tersebut menyatakan senang bisa menonton dan belajar, terlebih peserta didik selama pemutaran film pendek animasi tiga dimensi ikut berinteraksi semisal dalam satu adegan Yusuf membacakan ayat Surah Al-Lail dan peserta didikpun sontak mengikutinya. Pengambilan data tidak sebatas respon peserta didik melainkan tenaga pendidik juga termasuk, mengingat peserta didik belum bisa memutarkan film pendek animasi tiga dimensi secara mandiri dan juga dalam penggunaannya media pembelajaran ini secara khusus didesign agar tenaga pendidik dapat menerangkan apa yang ada di dalam film pendek animasi tiga dimensi.

Tabel 10 Hasil Uji Media Pengamatan Peserta Didik

\begin{tabular}{|l|c|c|c|c|c|c|}
\hline \multicolumn{1}{|c|}{ Nama siswa } & PM & PB & PK & PSE & Rata-rata & Kategori \\
\hline Nur Avisa & 1 & 1 & 1 & 0,75 & 0,93 & Layak \\
\hline Adiba Putri H. & 1 & 0,67 & 1 & 1 & 0,91 & Layak \\
\hline Putri Anindi & 0,5 & 0,67 & 1 & 1 & 0,80 & Layak \\
\hline Salsabillah & 0,5 & 0,67 & 1 & 1 & 0,80 & Layak \\
\hline Aan Pratama & 0 & 1 & 1 & 1 & 0,75 & Layak \\
\hline Raja Bahtiar & 1 & 1 & 1 & 0,5 & 0,88 & Layak \\
\hline Yana Lisa & 1 & 0,67 & 1 & 0,75 & 0,86 & Layak \\
\hline Khodijah & 0,5 & 0,34 & 1 & 1 & 0,71 & Layak \\
\hline Mumtaz & 0,5 & 1 & 1 & 0,75 & 0,81 & Layak \\
\hline Khaisha Putri S. & 0,5 & 1 & 1 & 0,75 & 0,81 & Layak \\
\hline Nabel Dwi P. & 0,5 & 1 & 1 & 0,5 & 0,81 & Layak \\
\hline Iqbal Ramadhan & 1 & 1 & 1 & 0,75 & 0,93 & Layak \\
\hline Yudi Purnama & 1 & 1 & 1 & 1 & 1 & Layak \\
\hline Dewi Prasetiowati & 0 & 1 & 1 & 0,75 & 0,69 & Layak \\
\hline Muliani Putri & 1 & 0,34 & 1 & 0,5 & 0,71 & Layak \\
\hline Aprilia Anissa P. & 0,5 & 0,67 & 1 & 0,75 & 0,98 & Layak \\
\hline Rehan Saputra & 1 & 1 & 1 & 1 & 1 & Layak \\
\hline Sabena Dwi & 1 & 0,34 & 1 & 0,5 & 0,71 & Layak \\
\hline Osena Fiska & 0,5 & 1 & 1 & 1 & 0,88 & Layak \\
\hline Nafila Riska & 0,5 & 1 & 1 & 0,75 & 0,81 & Layak \\
\hline \multicolumn{2}{|l|}{} & \multicolumn{1}{|c|}{} & & $\mathbf{0 , 8 4}$ & Layak \\
\hline
\end{tabular}

Hasil uji media terhadap pengamatan peserta didik mendapatkan skor 0,84 yang jika di lihat dalam (Romadhona, 2017) termasuk ke dalam kategori layak. Respon peserta didik selama 
pemutaran film pendek animasi tiga dimensi pun sebagian besar menyatakan senang karena bisa belajar dan menonton film pendek animasi tiga dimensi bersama teman yang lain.

\subsection{Keterbatasan Pengembangan}

Di dalam setiap pengembangan tentu saja terdapat keterbatasan yang dihadapi, berikut merupakan keterbatasan pengembangan media pembelajaran berbasis film pendek animasi tiga dimensi yang peneliti lakukan :

1. Peneliti menggunakan perangkat laptop dengan penjelasan sebagai berikut:

Processor : Intel(R) Celeron(R) CPU N3060 @ 1.60GHz 1.60 GHz

Installed RAM : 4,00 GB

Keterbatasan peneliti adalah dalam spesifikasi untuk perangkat pengembangan media film animasi, harusnya menggunakan perangkat lebih tinggi spesifikasi dari penjabaran di atas. Sehingga peneliti mengambil aplikasi Muvizu yang sesuai dengan spesifikasi laptop peneliti.

2. Aplikasi Muvizu yang digunakan untuk membantu mengembangkan media pembelajaran berbasis film pendek animasi tiga dimensi dengan materi Surah Al-Lail. Jenis aplikasi Muvizu ini merupakan aplikasi instan untuk pembuatan film animasi tiga dimensi akan tetapi kekurangan dari aplikasi tersebut yaitu tidak tersedia nya model pakaian-pakaian yang islami untuk menunjang tokoh atau karakter animasi dari setiap pemeran nya.

\section{Kesimpulan}

Hasil dari pengembangan media pembelajaran berbasis film pendek animasi tiga dimensi adalah terciptanya media pembelajaran yang berfungsi untuk menguatkan hafalan dan pemahaman makna Surah Al-Lail oleh peserta didik serta dapat digunakan oleh tenaga pendidik untuk pihak TAUD Al-Fatih Pekanbaru dalam proses pembelajaran.

Kelayakan media pembelajaran berbasis film pendek animasi tiga dimensi, review ahli materi dan ahli media, uji terbatas dan uji media. Review ahli materi tahap I dengan skor 87,75 kategori (sangat layak) dan revisi sesuai saran. Review ahli materi tahap II dengan skor 96,65 kategori (sangat layak). Review ahli media tahap I dengan skor 80,24 kategori (layak) dan revisi sesuai dengan saran. Review ahli media tahap II dengan skor 88,12 kategori (sangat layak) dan revisi sesuai saran. Kemudia review tahap III ahli media dengan skor 91,58 kategori (sangat layak). Pada tahap uji terbatas, pengamatan peserta didik dengan skor 0,60 kategori (layak), respon tenaga pendidik dengan skor 0,56 kategori (layak). Uji media pemakaian, pengamatan peserta didik dengan skor 0,84 kategori (layak), respon tenaga pendidik dengan skor 0,9 ketegori (layak). Dari keseluruhan prosedur kelayakan media yang dilakukan didapatkan hasil media pembelajaran berbasis film pendek animasi dengan kategori layak untuk digunakan dalam proses pembelajaran.

\section{Daftar Pustaka}

[1] F. Hidayat, "Kajian Psikologi Pembelajaran Hafal Quran bagi Anak Usia Dini," Proc. 2nd Annu. Conf. Islam. Early Child. Educ., vol. 2, pp. 83-94, 2017.

[2] P. Zakaria, S. Ismail, and I. P. I. Kiu, "PENGEMBANGAN INSTRUCTIONAL VIDEO BERBASIS MULTIMEDIA UNTUK MATERI SISTEM KOORDINAT Pery Zakaria 1 , Sumarno Ismail 2 , Irmawaty Pebrianni I. Kiu 3," J. Pendidik. Mat., vol. 1, no. 1, pp. 85-94, 2015.

[3] Rochmad, "(Mari wes) Desain Model Pengembangan Perangkat Pembelajaran Matematika," J. Kreano, vol. 3, no. 1, pp. 59-72, 2012.

[4] R. H. F. Romadhona, "PENGEMBANGAN VIDEO ANIMASI PEMBELAJARAN 'SALUT' PADA SUBTEMA TRANSPORTASI UNTUK ANAK KELOMPOK B TK MARSUDI SIWI SAWIT," 2017.

[5] P. B. Herlandy and M. Novalia, "Penerapan e-Learning pada Pembelajaran Komunikasi dalam Jaringan dengan Metode Blended learning Bagi Siswa SMK," J. Educ. Inform. 
Technol. Sci., vol. 1, no. 1, pp. 24-33, 2019.

[6] D. A. Sulistyaningrum, "Pengembangan Quantum Teaching Berbasis Video Pembelajaran Camtasia Pada Materi Permukaan Bumi Dan Cuaca," Profesi Pendidik. Dasar, vol. 4, no. 2, pp. 154-166, 2017.

[7] P. B. Herlandy, A. Satria, and E. Ismanto, "Simulasi Pengenalan dan Instalasi PC berbasis Augmented reality dengan Metode Single marker," J. Educ. Inform. Technol. Sci. Sci., vol. 1, no. 2, pp. 85-96, 2019. 